\title{
Financial Liberalization, Competition, and Bank Loan Quality
}

\author{
Xiaofen Chen \\ Truman State University
}

\begin{abstract}
The paper studies the relationship between financial liberalization, characterized by removing entry restrictions, and bank loan quality. It shows that if a banking market is liberalized, the opportunity cost of screening loan applicants is driven lower by competition. Thus, a bank facing an entry threat is more likely to invest in screening instead of relying on collateral requirements. Removing entry restrictions may improve loan quality stability and reduce correlation between bank performance and asset price fluctuations.
\end{abstract}

- JEL Classification: G2, L1

- Key words: financial liberalization, banking competition, screening, loan quality

\section{Introduction}

In the credit market, banks screen loan applicants by gathering information to reduce the adverse selection problem induced by information asymmetry and to ensure lending quality. If intensified competition following financial liberalization alters this effort, it can affect the overall lending quality and the stability of the banking sector. To better understand the effect of financial liberalization and the source of banking distress, this paper investigates whether lifting entry restrictions lowers banks' lending quality through reducing their screening incentives.

*Corresponding address: Truman State University, Social Science Division, Kirksville, MO, 63501, USA; (Tel) 660-785-4644; (Fax) 660-785-4337; (email) xiaofen@truman.edu. I am deeply grateful to Tito Cordella, Haizhou Huang, and Hans Haller for many fruitful discussions; to Giovanni Dell'Ariccia, Sudipta Saranghi, Andrew Feltenstein, and Thomas Gehrig, for many helpful suggestions. (C2005-Center for International Economics, Sejong Institution, All Rights Reserved. 
The paper presents a simple model demonstrating that after removing entry restrictions, banks are more likely to rely on screening loan applicants instead of on collateral requirements to deal with information asymmetry. Incorporating the recent finding of the association between asset price fluctuation and banking distress through the medium of collateralized loans, I argue that a competitive banking system is more likely to deliver higher lending quality and may be less vulnerable to asset price shocks.

A bank can reduce information asymmetry by screening loan applicants or requiring collateral. A drawback of relying on collateral requirements is that banks tend to be overly optimistic about collateralized loans and ignore their potential risk. ${ }^{1}$ In addition, fluctuations in asset prices increase the risk of banking distress. In the past several decades, asset prices have been fluctuating substantially and their sharp falls have often been associated with banking distress. The channels through which this flaw arises are discussed in a growing body of literature (see, for example, ECB (2000) and IMF (2000)). A popular explanation is that when asset prices are inflated, borrowers' borrowing ability increases with collateral values, and banks tend to lower their lending standards and extend excessive loans. When asset prices plummet, bank performance worsens as borrowers' insolvency increases and their collateral value falls. For this reason, as a risk sorting device, collateral requirements are inferior to loan applicant screening. A bank that invests in screening technology and relies less on collateral is more capable of coping with both market risk and default risk.

Current theoretical literature generally favors the view that financial liberalization would reduce screening activities and cause loan quality to deteriorate. ${ }^{2}$ Chan et al. (1986) use loan rates to parameterize competition and conclude that the marginal benefit of screening is reduced when loan rates decrease. Gehrig (1998) argues that competition may reduce screening efforts when the benefits from identifying profitable projects exceed the benefits of avoiding unprofitable projects. Schnitzer (1999) claims that the overall loan quality

${ }^{1}$ For example, during the bubble years, most Japanese banks made excessive and reckless collateralized loans, which turned bad quickly. The banks found they had loan loss reserves only against a fifth of problem loans because they typically did not make provisions for loans secured against property. See The Economist (2000) and Schaede (1996).

${ }^{2}$ There are papers arguing that intensified competition encourages excessive risk taking (Vives (2001) and Acharya (2001)), and lowers banks' monitoring efforts (Caminal and Matutes (2002)). Although related, these factors are not particularly considered here. 
in a duopoly banking market is lower than that of a monopoly bank. Manove et al. (2001) argue that screening in a competitive banking system is insufficient and below the socially optimal level. Marquez (2002) suggests that competition can reduce banks' screening ability by worsening the pool of loan applicants because of rejected borrowers. A similar view is also presented by Gehrig and Stenbacka (2001).

This paper will show that competition can positively impact a bank's screening effort since informational advantage increases a bank's ability to compete with its rivals. As compared with a new entrant, an existing bank has an advantage in gathering information due to its local knowledge or previous lending experiences. When threatened by a new entrant, it will have the incentive to exploit this informational advantage, instead of passively relying on collateral requirements and putting itself in the same position as an entrant. This consideration leads to a conclusion contrary to that of the above literature.

A distinguishing feature of the model is its focus on the effect of informational advantage on a bank's profitability. This focus leads to the modeling of a game involving banks' sequential screening and loan rate decisions, instead of treating the latter as a parameter. As a monopoly, a bank may lazily rely on collateral requirements and not invest in screening. However, when facing an entry threat, its profit will be driven to zero if it does not take advantage of its lower screening cost. In this sense, competition drives down the opportunity cost of screening and enhances its benefit. Thus, competitive pressure may induce banks to rely on information processing instead of collateral requirements. This implies that when a banking market is liberalized and entry occurs, banks' lending decisions are less likely to be affected by asset prices, and the quality of loans is less correlated with asset price fluctuations.

The paper is organized as follows: Section 2 presents the monopoly bank case with no entry threat. Section 3 analyzes the case when a bank is threatened by entry and compares it with the monopoly case. Section 4 contains final remarks.

\section{The Monopoly Case}

Following Gehrig (1998), consider a credit market where a monopoly bank faces two types of firms with the total measure normalized to one. The portions of the good type firms (g) and the bad type firms (b) are one half each. Each firm is endowed with a project that needs 1 unit of investment and can only be funded by 
borrowing from the bank. A good firm's project generates a return $z$ with probability $\pi_{\mathrm{g}}$ and a return 0 with probability $1-\pi_{\mathrm{g}}$; a bad firm's project has the same return $\mathrm{z}$ with a lower probability $\pi_{\mathrm{b}}$ and a return 0 with probability $1-\pi_{\mathrm{b}}$. Firms know their own types while the bank does not. However, the bank can observe the results of projects and enforce repayments from borrowers of successful projects. If a project fails, the firm pays nothing to the bank. Also assume that a good firm has a higher opportunity cost for conducting its project. That is, a good firm's reservation payoff is A > 0; and a bad firm's is 0 .

The bank has unlimited funding with a fixed gross rate 1 . Assume $\pi_{\mathrm{g}} z-1>0$, $\pi_{\mathrm{b}} z-1<0$, and $\frac{1}{2}\left(\pi_{g} z-1\right)+\frac{1}{2}\left(\pi_{b} z-1\right)=\frac{1}{2}\left(\pi_{g}+\pi_{b}\right) z-1<0$, so that funding a good project is beneficial for the economy, while funding a bad project or all good and bad projects is not. Further assume the bank can acquire information about a firm's status by screening the firm. For the purpose of simplicity, assume there is no differentiation in terms of screening levels. Once the bank screens a firm, it knows perfectly the status of the firm. Under this assumption, screening and using collateral are substitutes in that the bank has no need to use collateral as a risk sorting device once it decides to screen. Thus, the following analysis considers a bank's incentive for adopting screening versus collateral requirements. Further assume that screening each firm costs the bank a fixed amount of resources $\mathrm{C}$.

The bank can also require collateral to sort the borrowers. Let $\mathrm{K}$ denote the collateral requirement measured by its current market value. Assume that the bank discounts the value of collateral by the rate $\delta$, which accounts for the liquidation cost and, more importantly, the expected future change of the collateral's market value. The expected value of the collateral when it is liquidated is then $(1-\delta) K$. As argued by the IMF (2000), due to reasons such as lack of supply flexibility in the short run, asset prices can fluctuate wildly. With uncertainty and subjectivity in forming expectations, the expected collateral value could be well above its fundamental value, inducing a potential risk of bank insolvency when asset prices fall sharply.

\section{A. Using Collateral}

First, consider the case of using collateral. Denote a good firm's and a bad firm's expected payoffs from a loan with loan rate $r$ and collateral $\mathrm{K}$ by $\varphi_{\mathrm{g}}$ and $\varphi \mathrm{b}$, respectively.

Thus, 


$$
\begin{aligned}
& \varphi_{g}=\pi_{g}(z-r)-\left(1-\pi_{g}\right) K ; \\
& \varphi_{b}=\pi_{b}(z-r)-\left(1-\pi_{b}\right) K .
\end{aligned}
$$

Figure 1 shows the isopayoff lines of both types of firms, corresponding to their reservation payoffs. A firm applies for a loan if the bank's offer is located below its isopayoff line. When the bank's offer is the same as a firm's reservation payoff, assume that a good firm applies for a loan but a bad firm does not.

Following the reasoning in Bester (1985) and Besanko and Thakor (1987), the bank can choose the loan rate and collateral level in the shaded area shown in figure 1 such that only good firms are interested in applying for a loan. The bank's optimal choice for this strategy is then point $\mathrm{Q}$, the intersection of the two isopayoff lines. To see this, notice the bank's profit $\Psi(K, r)$ is

$$
\begin{aligned}
\Psi(K, r) & =\frac{1}{2}\left[\pi_{g} r+\left(1-\pi_{g}\right)(1-\delta) K-1\right] \\
& =\frac{1}{2}\left[\pi_{g} z-\delta\left(1-\pi_{g}\right) K-\varphi_{g}-1\right]
\end{aligned}
$$

Given $\varphi_{\mathrm{g}}$, the bank's profit $\Psi(K, r)$ decreases with $K$.

Notice that at $\mathrm{Q}, \varphi_{\mathrm{g}}=\mathrm{A}$, and $\varphi_{\mathrm{b}}=0$. Solving them yields a monopoly bank's optimal collateral level $K_{m}$ and loan rate $r_{m}^{K}$ :

Figure 1. The monopoly case.

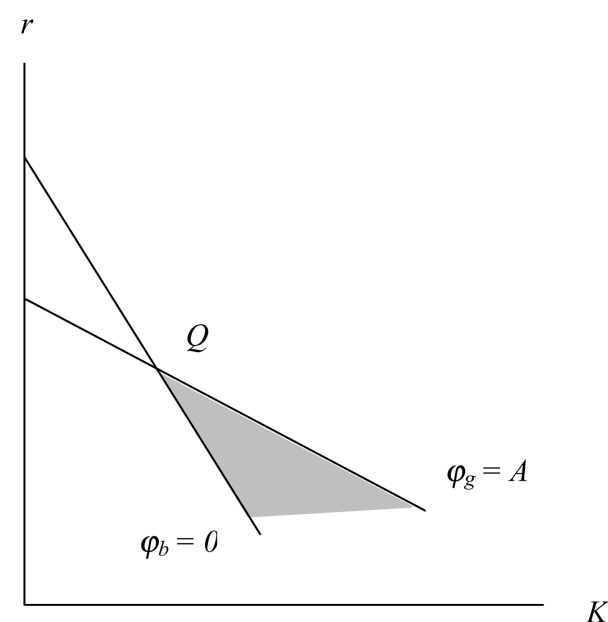




$$
\begin{gathered}
K_{m}=\frac{\pi_{b}}{\pi_{g}-\pi_{b}} A \\
r_{m}^{K}=z-\frac{1-\pi_{b}}{\pi_{g}-\pi_{b}} A
\end{gathered}
$$

Correspondingly, its expected profit at $\mathrm{Q}\left(K_{m}, r_{m}^{K}\right)$ is:

$$
\begin{aligned}
\Psi_{m}^{K} & =\frac{1}{2}\left[\pi_{g} r_{m}^{K}+\left(1-\pi_{g}\right)(1-\delta) K_{m}-1\right] \\
& =\frac{1}{2}\left(\pi_{g} z-A-1\right)-\frac{1}{2} \delta\left(1-\pi_{g}\right) K_{m} \\
& \equiv \frac{1}{2}\left(\pi_{g} z-A-1\right)-D_{m}
\end{aligned}
$$

The last item $D_{m} \equiv \frac{1}{2} \delta\left(1-\pi_{g}\right) K_{m}=\frac{1}{2} \frac{\delta\left(1-\pi_{g}\right) \pi_{b}}{\pi_{g}-\pi_{b}}$ A stands for the expected cost of using collateral.

In order for $\Psi_{m}^{K}$ to be positive, assume:

$$
A<\left(\pi_{g} z-1\right) \frac{\pi_{g}-\pi_{b}}{\pi_{g}-\pi_{b}+\delta\left(1-\pi_{g}\right) \pi_{b}}
$$

Note that when asset prices plunge unexpectedly, the value of collateral declines significantly when it is liquidated. In other words, depending on the movement of asset prices, the true $\delta$, and hence the actual cost of using collateral, can deviate from its expected value greatly, resulting in correlation between bank profits and asset price fluctuations.

\section{B. Screening Loan Applicants}

When the monopoly bank conducts screening, a loan applicant's status will be revealed. In order for a good firm to demand a loan, the monopoly bank must ensure that its expected payoff is no less than its reservation payoff, i.e.,

$$
\varphi_{g}=\pi_{g}(z-r) \geqslant \mathrm{A} .
$$

Hence, the bank would choose the loan rate

$$
r_{m}^{s}=z-\frac{A}{\pi_{g}},
$$


at which its expected profit is

$$
\begin{aligned}
\Psi_{m}^{S} & =\frac{1}{2}\left(\pi_{g} r_{m}^{S}-1\right)-C \\
& =\frac{1}{2}\left(\pi_{g} z-A-1\right)-C .
\end{aligned}
$$

As we can see by comparing (2) with (4), the difference in the expected profits between using collateral and conducting screening lies in their costs. The monopoly bank will select to screen if screening returns a higher profit, i.e., if the cost of screening is lower than the expected cost of using collateral:

$$
C \leqslant D_{m} \equiv \frac{1}{2} \frac{\delta\left(1-\pi_{g}\right) \pi_{b}}{\pi_{g}-\pi_{b}} A
$$

\section{The Case with an Entrant}

Now consider an incumbent bank, bank 1, facing the threat of losing market share to a potential entrant, bank 2, after removing entry restrictions. As a new bank, bank 2 lacks the local knowledge and has no previous lending experiences. It is more costly for bank 2 to collect information and make informed lending decisions. In contrast, bank 1 has an advantage in gathering information and has lower screening cost. To model this fact in a simple form, I assume that only one bank, bank 1, has the screening technology. With this assumption, bank 1 has the choice of either using collateral or adopting the screening technology, while bank 2 can only use collateral. Also assume a good firm would go to bank 1 if it expects the same payoff from both banks. The timing of the game is as follows:

- Bank 1 decides to use collateral or screening;

- Bank 1 announces its collateral requirement or screening level, and bank 2 announces its collateral requirement at the same time;

- Both banks announce their loan rates;

- Each firm picks a bank and applies for a loan;

- Bank 1 screens applicants if it makes this choice at the first stage;

- Both banks grant loans.

I proceed by first analyzing the subgame with bank 1 adopting screening technology. 
Suppose bank 1 chooses to screen and charges a loan rate $r_{1}$; bank 2 competes with bank 1 through collateral requirement $K_{2}$ and loan rate $r_{2}$. Since bank 1 knows an applicant's status, a good firm's and a bad firm's expected payoffs from bank 1 are $\pi_{\mathrm{g}}\left(z-r_{1}\right)$ and 0 , respectively.

Let $\varphi_{g, i}$ and $\varphi_{b, i}$ denote a good and a bad firm's expected payoas from bank $i$, for $i=1,2$. Figure 2 shows both types of firms' isopayoff lines when borrowing from bank 2 at their reservation payoff levels $\left(\varphi_{g, 2}=\mathrm{A}\right.$, and $\left.\varphi_{b, 2}=0\right)$, and the isoprofit line for bank 2 at the break-even level $\left(\Psi_{2}\left(K_{2}, r_{2}\right)=0\right)$ when all its applicants are good firms. At Q, where $\varphi_{g, 2}=$ A and $\varphi_{b, 2}=0$, bank 2's profit would be positive and the same as a monopoly bank's if it can keep the good firms. Thus, the line $\Psi_{2}\left(K_{2}, r_{2}\right)=0$ is located below Q. Denote its intersection with the line $\varphi_{b, 2}=0$ as point $\mathrm{E}$, and a good firm's expected payoff from bank 2 at $E$ as $\varphi_{g}^{o}$.

As we will see, the equilibrium outcome with bank 1 screening loan applicants depends on its screening technology.

Definition 1 The screening technology is sufficiently eiffcient if $\Psi_{1}\left(r_{1}^{*}\right)=$ $\frac{1}{2}\left(\pi_{g} r_{1}^{*}-1\right)-C \geqslant 0$, where $r_{1}^{*}$ satisfies $\varphi_{g, 1}\left(r_{1}^{*}\right)=\varphi_{g}^{o}$.

To find $r_{1}^{*}$, first find bank 2's corresponding loan rate and collateral level $\left(K_{E}, r_{\mathrm{E}}\right)$ at $E$, which satisfy the conditions $\Psi_{2}\left(K_{E}, r_{E}\right)=\frac{1}{2}\left[\pi_{g} r_{E}+\left(1-\pi_{g}\right)(1-\delta) K_{E}-1\right]=0$ and $\varphi_{b, 2}=\pi_{b}\left(z-r_{\mathrm{E}}\right)-\left(1-\pi_{b}\right) K_{\mathrm{E}}=0$. Solving them obtains $K_{E}, r_{\mathrm{E}}$, and $\varphi_{g}^{o}$ :

Figure 2. The case with an entrant.

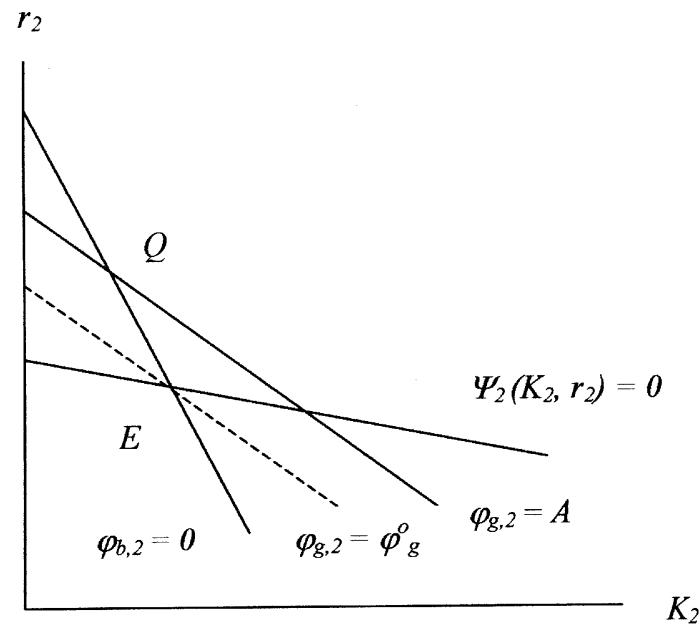




$$
\begin{aligned}
K_{E} & =\frac{\pi_{b}\left(\pi_{g} z-1\right)}{\pi_{g}-\pi_{b}+\delta\left(1-\pi_{g}\right) \pi_{b}} ; \\
r_{E} & =z-\frac{\left(1-\pi_{b}\right)\left(\pi_{g} z-1\right)}{\pi_{g}-\pi_{b}+\delta\left(1-\pi_{g}\right) \pi_{b}} ; \\
\varphi_{g}^{o} & =\pi_{g}\left(z-r_{E}\right)-\left(1-\pi_{g}\right) K_{E} \\
& =\frac{\left(\pi_{g}-\pi_{b}\right)\left(\pi_{g} z-1\right)}{\pi_{g}-\pi_{b}+\delta\left(1-\pi_{g}\right) \pi_{b}} .
\end{aligned}
$$

From $\varphi_{g, 1}\left(r_{1}^{*}\right)=\pi_{g}\left(z-r_{1}^{*}\right)=\varphi_{g}^{o}$

$$
r_{1}^{*}=z-\frac{\left(\pi_{g}-\pi_{b}\right)\left(\pi_{g} z-1\right)}{\pi_{g}\left[\pi_{g}-\pi_{b}+\delta\left(1-\pi_{g}\right) \pi_{b}\right]} .
$$

Thus, an alternative way to define sufficient efficiency of the screening technology is that the screening cost satisfies:

$$
C \leqslant \frac{1}{2}\left(\pi_{g} z-1\right) \frac{\delta\left(1-\pi_{g}\right) \pi_{b}}{\pi_{g}-\pi_{b}+\delta\left(1-\pi_{g}\right) \pi_{b}} \equiv D_{c}
$$

Lemma 1 When bank 1's screening technology is sufficiently efficient, an equilibrium at which bank 1 screens loan applicants has the following features:

- Bank 1 announces $r_{1}^{*}$ as specified in (6);

- Bank 2 offers $\left(K_{2}^{*}, r_{2}^{*}\right)$ such that $\varphi_{g, 2}^{*}\left(K_{2}^{*}, r_{2}^{*}\right)=\varphi_{g}^{o}$ and $\varphi_{b, 2}^{*}\left(K_{2}^{*}, r_{2}^{*}\right) \leqslant 0$.

Proof. Suppose bank 1 offers $r_{1}^{\prime}>r_{1}^{*}$, at which $A \leq \varphi_{g, 1}^{\prime}\left(r_{1}^{\prime}\right)<\varphi_{g}^{o}$. Bank 2 can offer $\left(K_{E}, r_{2}-\varepsilon\right)$, where $\left(K_{E}, r_{2}\right)$ satisfies $\varphi_{g, 2}^{\prime}\left(K_{E}, r_{2}\right)=\varphi_{g, 1}<\varphi_{g}^{o}$, and $\varepsilon$ is a small positive number. Since $\varphi_{g}\left(K_{E}, r_{E}\right)=\varphi_{g}^{o}$ and $\varphi_{b}\left(K_{E}, r_{E}\right)=0, r_{2}$ must be greater than $r_{\mathrm{E}}$, and $\varphi_{b, 2}\left(K_{E}, r_{2}^{\prime}\right)<0$. Hence, when $\varepsilon$ is sufficiently small, bank 2 can attract good firms only and earn a positive profit, which is $\Psi_{2}\left(K_{E}, r_{2}^{\prime}-\varepsilon\right)=$ $\frac{1}{2}\left[\pi_{g} z-\delta\left(1-\pi_{g}\right) K_{E}-\varphi_{g, 2}-1\right]>\frac{1}{2}\left[\pi_{g} z-\delta\left(1-\pi_{g}\right) K_{E}-\varphi_{g}^{o}-1\right]=0$, according to (1). In turn, bank 1 should match bank 2's offer to good firms, i.e., lower its loan rate such that a good firm expects the same payoff from bank 1 . Hence, the loan rate $r_{1}$ is not an equilibrium offer.

Suppose bank 1 announces $r_{1}^{\prime \prime}<r_{1}^{*}$ where $\varphi_{g, 1}^{\prime \prime}\left(r_{1}^{\prime \prime}\right)>\varphi_{g}^{o}$. Note that bank 2 has no way to beat bank 1's offer to good firms without making a loss. Its best response is to stay out of the market. Bank 1 should then raise its loan rate and increase its profit. Thus, $r_{2}^{\prime \prime}$ is not an equilibrium loan rate either. 
If bank 1 sets its loan rate at $r_{1}^{*}$, then $\varphi_{g, 1}^{*}\left(r_{1}^{*}\right)=\varphi_{g}^{o}$ and $\varphi_{b, 1}^{*}=0$. Suppose bank 2 attempts to attract good firms only. It should offer $\left(K_{2}, r_{2}\right)$ such that $\varphi_{g, 2}>$ $\varphi_{g}^{o}$ and $\varphi_{b, 2} \leqslant 0$. In this case, it would make a loss, as seen in figure 2 . Thus, $\left(K_{2}^{*}, r_{2}^{*}\right)$ such that $\varphi_{g, 2}^{*}\left(K_{2}^{*}, r_{2}^{*}\right)=\varphi_{g}^{o}$ and $\varphi_{b, 2}^{*}\left(K_{2}^{*}, r_{2}^{*}\right) \leqslant 0$ is a best response, at which no firm applies for a loan from bank 2 . Given such an offer from bank 2, bank 1's best response is $r_{1}^{*}$ to match bank 2's offer to good firms.

At $r_{1}^{*}, \Psi_{1}\left(r_{1}^{*}\right) \geqslant 0$ by the condition of sufficient efficiency of the screening technology. Also notice that when assumption (3) holds, $r_{1}^{*}<z-\frac{A}{\pi_{g}}$. Therefore, $r_{1}^{*}$ is lower than the interest rate a monopoly bank would charge whển it screens.

If bank 1's screening technology is inefficient, i.e., if its profit $\Psi_{1}\left(r_{1}^{*}\right)<0$ when $\varphi_{g, 1}\left(r_{1}^{*}\right)=\varphi_{g}^{o}$, bank 2 can drive bank 1 out of the market if it sets $\left(K_{2}, r_{2}\right)$ such that $\varphi_{b, 2}=0$ and $\varphi_{g, 2}=\overline{\varphi_{g, 1}}+\varepsilon$, where $\overline{\varphi_{g, 1}}$ is a good firm's expected payoff from bank 1 at bank 1's break-even loan rate, and $\varepsilon$ is a sufficiently small positive number.

Next I consider the case in which bank 1 requires collateral. In this case, $\varphi_{g, i}=$ $\pi_{\mathrm{g}}\left(z-r_{i}\right)-\left(1-\pi_{\mathrm{g}}\right) K_{i}$ and $\varphi_{b, i}=\pi_{b}\left(z-r_{i}\right)-\left(1-\pi_{b}\right) K_{i}$, where $i=1,2$. To attract good firms only, a bank tends to set its collateral requirement higher than that of the other bank. To see this, suppose $\varphi_{g, 1}>\varphi_{g, 2}$ and $\varphi_{b, 1}<\varphi_{b, 2}$. Since $\pi_{b}\left(\varphi_{g, 1}-\varphi_{g, 2}\right)$ $-\pi_{g}\left(\varphi_{b, 1}-\varphi_{b, 2}\right)=\left(\pi_{g}-\pi_{b}\right)\left(K_{1}-K_{2}\right)$ must be positive, $K_{1}$ must be greater than $K_{2}$. However, banks' expected profits will be eroded by offering higher expected payoffs to good firms in order to attract them and requiring higher collateral to keep the bad firms away, as shown in (1). Intuition suggests that both banks will end up earning zero profits as a result of competition.

Lemma 2 Each bank earns a zero profit if bank 1 requires collateral.

Proof. If bank $i$ offers $\left(K_{i}, r_{i}\right)$ such that $\varphi_{g, i}<\varphi_{g}^{o}$, bank $j$ can undercut bank $i$ and earn a positive profit, and bank $i$ should again undercut bank $j$. On the other hand, if bank $i$ offers $\left(K_{i}, r_{i}\right)$ such that $\varphi_{g, i}>\varphi_{g}^{o}$, the best response for bank $j$ is to stay out of the market and bank $i$ will have to bear a loss. Thus, the two banks' offers must give the same expected payoff $\varphi_{g}^{o}$ for a good firm at equilibrium. In this case, good firms go to bank 1 . In order not to make a loss, the only choice for bank 1 is to offer $E\left(K_{\mathrm{E}}, r_{\mathrm{E}}\right)$, where $\Psi_{1}=0$. Given such an offer by bank 1, bank 2 cannot undercut it without a loss. Thus, extending the same offer $E\left(K_{\mathrm{E}}, r_{\mathrm{E}}\right)$ or an offer located anywhere on a good firm's isopayoff line $\varphi_{\mathrm{g}}=\varphi_{g}^{o}$ below $E$ is a best response for bank 2. If bank 2 announces such a strategy, $\mathrm{E}$ is bank 1's best response, at which firms go to bank 1 and bank 1 breaks even. Thus, at 
equilibrium, both banks earn zero profits.

Now that bank 1 breaks even by requiring collateral, the condition for an equilibrium with bank 1 screening loan applicants is that the screening technology is sufficiently efficient, i.e., condition (7) holds. When this condition is satisfied, the equilibrium described in lemma 1 is a subgame perfect equilibrium. Comparing this condition with the condition for a monopoly bank to screen (equation (5)), one observes that bank 1, the bank threatened by entry, is more likely to screen than is the monopoly bank.

Lemma 3 The upper limit of the screening cost for a monopoly bank to screen is lower than that for a bank threatened by entry.

Proof. From (3), we know $\left(\pi_{g} z-1\right) \frac{\pi_{g}-\pi_{b}}{\pi_{g}-\pi_{b}+\left(1-\pi_{g}\right) \pi_{b} \delta}>A$; thus

$$
\begin{aligned}
D_{c} & \equiv \frac{1}{2}\left(\pi_{g} z-1\right) \frac{\left(1-\pi_{g}\right) \pi_{b} \delta}{\pi_{g}-\pi_{b}+\left(1-\pi_{g}\right) \pi_{b} \delta} \\
& =\frac{1}{2} \frac{\left(1-\pi_{g}\right) \pi_{b} \delta}{\pi_{g}-\pi_{b}} *\left(\pi_{g} z-1\right) \frac{\pi_{g}-\pi_{b}}{\pi_{g}-\pi_{b}+\left(1-\pi_{g}\right) \pi_{b} \delta} \\
& >\frac{1}{2} \frac{\left(1-\pi_{g}\right) \pi_{b} \delta}{\pi_{g}-\pi_{b}} A \\
& =D_{m}
\end{aligned}
$$

The above lemma indicates that even though the loan rate is driven lower, a bank facing an entry threat has a wider range of parameters where screening prevails.

Whenever it is optimal for a monopoly bank to screen loan applicants, it is also optimal for a bank facing an entry threat to do so. When the screening cost lies in the interval $\left(D_{m}, D_{c}\right]$, a bank would invest in screening when facing an entry threat, while it would give up screening if it is a monopoly. The reason is that a monopoly bank can ensure a positive profit by requiring collateral; however, when there exists competition from an entrant, its profit from requiring collateral is driven down to zero. Thus, the opportunity cost of screening is lower under competition.

Not surprisingly, the impact of market structure on screening activities hinges on the cost of the screening technology. When screening is too costly $\left(C>D_{\mathrm{c}}\right)$, a bank gives up screening with or without an entry threat. In this case, the information advantage 
of being an incumbent bank disappears.

\section{Final Remarks}

Depending on the cost of screening loan applicants, a monopoly bank may rely on collateral instead of investing in costly screening activities. Its performance may therefore be correlated with asset price cycles. Thus, fluctuations of asset prices are associated with instability of bank loan quality and are a source of banking crisis. Using a simple formulation, this model finds that this correlation can be reduced when a banking market is liberalized. Competition drives banks' profit from issuing collateralized loans to zero, resulting in a lower opportunity cost of screening loan applicants, even though loan rates are driven lower. Thus, after removing entry restrictions, banks are more likely to invest in screening technology and reduce the reliance on collateral. As a result, their ability to cope with market and default risks may be strengthened. Other things being equal, the banking industry may become less vulnerable to asset price shocks. This result is contrary to what is commonly believed.

Some empirical findings seem to support this argument. According to Jayaratne and Strahan (1996), lifting intrastate restrictions contributed to the substantial improvement in loan quality of the US banking sector. Rizvi (2001) and Isik and Hassan (2003) both find evidence of improved bank efficiency and performance as a result of increased competition following the banking deregulation reforms in Pakistan and Turkey, respectively.

Several additional issues related to the model and its results need to be addressed. First, the model adopts a simple one-period formulation and it could be further studied in a more complex dynamic setting. Nonetheless, there is no obvious reason that a dynamic modeling approach should produce fundamental differences. In a dynamic setting, when possible changes of a firm's status from one period to the next period are taken into account, it is necessary for a bank to conduct screening in each period. In this sense, each period may be taken independently, and the incumbent bank's informational advantage may be viewed partly as a benefit of the previous lending relationship with the firms. A second concern is that incumbent banks and new entrants may have different collateral costs. For example, it may be more inconvenient and more costly for foreign banks to liquidate collateral. An extension of the model may take this possibility into account. 
The model has a result that the entrant does not acquire a market share. This result coincides with the fact that removing entry restrictions often does not result in significant foreign entry, and that foreign banks usually have small market shares.

However, competitive pressure created by the removal of entry restrictions does not disappear for this reason. A foreign bank may enter into a host country in the form of a representative office and does not directly engage in competition with domestic banks, but the convenience of its further permeation into the local market can pose a persistent and significant threat to the domestic banks.

Finally, the positive effect of lifting entry restrictions on screening activities depends on the effciency of screening technology. When the screening technology is too costly, neither the monopoly bank nor the bank threatened by entry screens. In this sense, financial liberalization can result in better effects when the banking system has developed more efficient screening technology. Some researchers point out that the sequence of financial liberalization is crucial as incomplete reforms such as retaining soft budget constraints, imperfect legal systems, and the shock of regime changes that introduce inexperienced and unskilled players ${ }^{3}$ - can contribute to the weakness of the banking sector. However, as indicated by Dobson and Jacquet (1998), many of these problems are not caused, but rather revealed by financial liberalization, and should be distinguished from the more fundamental issues such as the one considered in this paper.

Received 6 January 2003, Accepted 11 November 2003

\section{References}

Acharya, V. V. (2001), "Competition among Banks, Capital Requirements and International Spillovers", Economic Notes, 30 (3), 337-58.

Besanko, D. and Thakor, A. V. (1987), "Collateral and Rationing: Sorting Equilibria in Monopolistic and Competitive Credit Markets", International Economic Review, 28 (3), 671-689.

Bester, H. (1985), "Screening vs Rationing in Credit Markets with Imperfect Information", American Economic Review, 57, 850-855.

Caminal, R. and Matutes, C. (2002), "Can Competition in the Credit Market Be Excessive?", UFAE (Unitat de Fonaments de l'Anàlisi Econòmica) and IAE (Institut d'Anàlisi Econòmica) working paper 527.02.

Chan, Y., Greenbaum, S. I., and Thakor, A. V. (1986), "Information Reusability, Compe-

${ }^{3}$ See Lindgren et al. (1996), pp. 100, and Honohan (2000). 
tition and Bank Asset Quality", Journal of Banking and Finance, 10, 243-253.

Dobson, W. and Jacquet, P. (1998), Financial Services Liberalization in the WTO, Washington, D. C., Institute for International Economics, 32-46.

ECB (European Central Bank) (2000), Asset Prices and Banking Stability, prepared by the Banking Supervision Committee (BSC), April.

The Economist (2000), "From Bad to Worse", September 23rd issue, 92-93.

Gehrig, T. (1998), "Screening, Cross-border Banking, and the Allocation of Credit", Research in Economics, 52, 387-407.

Gehrig, T. and Stenbacka, R. (2001), "Banking Competition, Financial Stability, Lending Cycles and Screening", Centre for Economic Policy Research discussion paper 2915.

Honohan, P. (2000), "Banking System Failures in Developing and Transition Countries: Diagnosis and Prediction", Economic Notes, 29, 83-109.

IMF (International Monetary Fund) (2000), “Asset Prices and the Business Cycle”, World Economy Outlook, May.

Isik, I. and Hassan, M. K. (2003), "Financial Deregulation and Total Factor Productivity Change: An Empirical Study of Turkish Commercial Banks", Journal of Banking and Finance, 27 (8), 1455-85.

Jayaratne, J., and Strahan, P. E. (1996), "The Finance-Growth Nexus: Evidence From Bank Branch Deregulation”, Quarterly Journal of Economics, August, 111 (3), 63970.

Lindgren, C., Garcia, G., and Saal, M. I. (1996), Bank Soundness and Macroeconomic Policy, International Monetary Fund.

Manove, M., Padilla, A. J., and Pagano, M. (2001), "Collateral versus Project Screening: A Model of Lazy Banks", RAND Journal of Economics, 32 (4), 726-44.

Marquez, R. (2002), "Competition, Adverse Selection, and Information Dispersion in the Banking Industry”, Review of Financial Studies, 15 (3), 901-26.

Rizvi, S. F. A. (2001), "Post-liberalization Efficiency and Productivity of the Banking Sector in Pakistan", Pakistan Development Review, 40 (4), 605-30.

Schaede, U. (1996), “The 1995 Financial Crisis in Japan”, Berkeley Roundtable on the International Economy Working Paper 85, University of California at Berkeley.

Schnitzer, M. (1999), "On the Role of Bank Competition for Corporate Finance and Corporate Control in Transition Economies", Journal of Institutional and Theoretical Economics, 155, 22-46.

Vives, X. (2001), "Competition in the Changing World of Banking", Oxford Review of Economic Policy, 17 (4), 535-547. 